\title{
An Ultra-Elderly Case of Acute-Onset Autoimmune Type 1 Diabetes Mellitus
}

\author{
Hiroshi Yamaguchia, d, Takafumi Kanadani ${ }^{\mathrm{b}}$, Masumi Ohno ${ }^{\mathrm{c}}$, Atsuhisa Shirakami ${ }^{\mathrm{a}}$
}

\begin{abstract}
We herein described a 96-year-old woman who was referred to our hospital for a drowsy state. Since her blood glucose level was 600 $\mathrm{mg} / \mathrm{dL}, \mathrm{HbA} 1 \mathrm{c}$ was $11.2 \%$, and serum $\beta$-ketone bodies were low, she was diagnosed with diabetic ketosis and hyperglycemic hyperosmolar state. Acute-onset type 1 diabetes mellitus was diagnosed based on the diagnostic criteria for acute-onset type 1 diabetes mellitus (2012) by the Committee of the Japan Diabetes Society. There are currently no epidemiological data available for the elderly with acute-onset type 1 diabetes in the Japanese population. This case revealed that acute type 1 diabetes may develop not only in the young-old or old-old, but also in the ultra-elderly. To the best of our knowledge, our case is the oldest among ultra-elderly cases of acute-onset type 1 diabetes mellitus.
\end{abstract}

Keywords: Acute onset; Autoimmune; Type 1 diabetes mellitus; Elderly; Frailty; Honeymoon period

\section{Introduction}

Type 1 diabetes is characterized by the destruction of pancreatic $\beta$ cells, which ultimately leads to an absolute deficiency in the secretion of insulin and requires regular blood glucose monitoring and treatment with insulin. In Japan, type 1 diabetes is classified as fulminant, acute-onset, or slowly progressive based on its onset and progression [1]. Among patients who develop ketosis or diabetic ketoacidosis within 3 months of the onset of hyperglycemic symptoms and require insulin

Manuscript accepted for publication April 11, 2016

aDepartment of Diabetology and Metabolic Medicine, Tokushima Prefectural Central Hospital, Kuramoto, 1-10-3, Tokushima 770-8539, Japan

${ }^{b}$ The Center for Clinical Education, Tokushima Prefectural Central Hospital, Kuramoto, 1-10-3, Tokushima 770-8539, Japan

'Department of Internal Medicine, Ohno Hospital, Donari-cho, Awa City, Tokushima 771-1506, Japan

${ }^{\mathrm{d} C}$ Corresponding Author: Hiroshi Yamaguchi, Department of Diabetology and Metabolic Medicine, Tokushima Prefectural Central Hospital, Kuramoto, 1-10-3, Tokushima 770-8539, Japan. Email: futuyaso007@yahoo.co.jp

doi: http://dx.doi.org/10.14740/jem346w treatment continuously after the diagnosis of diabetes, those with anti-islet autoantibodies are diagnosed with acute-onset type 1 diabetes mellitus (autoimmune).

Although the onset of type 1 diabetes can develop at any age, it commonly presents in childhood or young adulthood. Type 1 diabetes accounts for approximately 5\% of all cases of diabetes in Japan. Since there are currently no epidemiological data available for adulthood, the exact incidence of type 1 diabetes in the elderly remains unclear.

\section{Case Report}

A 96-year-old woman was referred to our hospital for a drowsy state. She had resided in a nursing home for 2 years before her admission due to senile dementia. She was losing her appetite and had lost the ability to stand 2 months ago. These conditions were attributed to her advanced age. She had a low-grade fever and cold-like symptoms, such as a nasal discharge and cough, 1 week before her admission. Since her level of consciousness had gradually worsened and she had become somnolent, she was taken to our hospital by ambulance. She was bedridden and her responses were slow. She had a previous medical history of hypertension and mild heart failure, but did not have a history of diabetes or a family history of type 1 or type 2 diabetes. On admission, the results of her physical examination and vital signs were as follows: height, $143 \mathrm{~cm}$; body weight, $34.0 \mathrm{~kg}$; BMI, $16.6 \mathrm{~kg} / \mathrm{m}^{2}$; body temperature, $35.7{ }^{\circ} \mathrm{C}$; heart rate, 64 beats/min; $\mathrm{SpO}_{2}, 93 \%$ (on room air); respiratory rate, 14 breaths/min; and blood pressure, 220/70 mm Hg. Her blood glucose level was $600 \mathrm{mg} / \mathrm{dL}$, HbAlc was $11.2 \%$, and serum osmolality was $323 \mathrm{mOsm} / \mathrm{kg}$. Although urine ketone bodies were negative, blood ketone bodies were mildly elevated (Table 1). Therefore, she was diagnosed with diabetic ketosis and hyperglycemic hyperosmolar state.

The continuous intravenous infusion of fast-acting insulin and saline were initiated. According to the diagnostic criteria of type 1 diabetes mellitus proposed by the Japan Diabetes Society [1], the diagnosis of acute-onset autoimmune type 1 diabetes mellitus was made by a rise in the titer of the anti-GAD antibody $(797.0 \mathrm{U} / \mathrm{mL})$ and decrease in endogenous insulin secretory capacity (fasting serum C-peptide: $0.4 \mathrm{ng} / \mathrm{mL}$ ). Her HLA genotype was DRB1*13 and she did not have class II human leukocyte antigen (HLA) (DR 4, 9), which is associated 
Table 1. Laboratory Data

\begin{tabular}{|c|c|}
\hline \multicolumn{2}{|l|}{ Urinalysis } \\
\hline Protein & - \\
\hline Glucose & $3+$ \\
\hline Ketone bodies & - \\
\hline \multicolumn{2}{|l|}{ Blood cell count } \\
\hline WBC & $6,100 / \mu \mathrm{L}$ \\
\hline $\mathrm{Hb}$ & $10.1 \mathrm{~g} / \mathrm{dL}$ \\
\hline Plt & $20.9 \times 10^{4} / \mu \mathrm{L}$ \\
\hline \multicolumn{2}{|l|}{ Blood chemistry } \\
\hline T-bil & $0.3 \mathrm{mg} / \mathrm{dL}$ \\
\hline AST & $15 \mathrm{U} / \mathrm{L}$ \\
\hline ALT & $15 \mathrm{U} / \mathrm{L}$ \\
\hline ALP & $421 \mathrm{U} / \mathrm{L}$ \\
\hline AMY & $20 \mathrm{U} / \mathrm{L}$ \\
\hline BUN & $34.8 \mathrm{mg} / \mathrm{dL}$ \\
\hline $\mathrm{Cr}$ & $0.96 \mathrm{mg} / \mathrm{dL}$ \\
\hline $\mathrm{Na}$ & $137.7 \mathrm{mEq} / \mathrm{L}$ \\
\hline $\mathrm{K}$ & $4.28 \mathrm{mEq} / \mathrm{L}$ \\
\hline $\mathrm{Cl}$ & $101.1 \mathrm{mEq} / \mathrm{L}$ \\
\hline Alb & $3.3 \mathrm{~g} / \mathrm{dL}$ \\
\hline LDL-C & $148 \mathrm{mg} / \mathrm{dL}$ \\
\hline HDL-C & $29.7 \mathrm{mg} / \mathrm{dL}$ \\
\hline $\mathrm{TG}$ & $145 \mathrm{mg} / \mathrm{dL}$ \\
\hline Posm & $323 \mathrm{mOsm} / \mathrm{kg}$ \\
\hline \multicolumn{2}{|l|}{ Diabetes-related data } \\
\hline PG & $630 \mathrm{mg} / \mathrm{dL}$ \\
\hline HbAlc & $11.20 \%$ \\
\hline GA & $48.30 \%$ \\
\hline GAD Ab & $797 \mathrm{U} / \mathrm{mL}$ \\
\hline $\mathrm{IA}-2 \mathrm{Ab}$ & $0.4 \mathrm{U} / \mathrm{mL}$ \\
\hline S-CPR & $0.4 \mathrm{ng} / \mathrm{mL}$ \\
\hline $\mathrm{AcAc}$ & $206 \mu \mathrm{M} / \mathrm{L}$ \\
\hline 3-OHBA & $276 \mu \mathrm{M} / \mathrm{L}$ \\
\hline \multicolumn{2}{|l|}{ Serological test } \\
\hline CRP & $4.5 \mathrm{mg} / \mathrm{dL}$ \\
\hline ANA & - \\
\hline \multicolumn{2}{|c|}{ Endocrine examination } \\
\hline Free T3 & $1.4 \mathrm{pg} / \mathrm{mL}$ \\
\hline Free T4 & $1.2 \mathrm{ng} / \mathrm{dL}$ \\
\hline $\mathrm{TSH}$ & $0.706 \mu \mathrm{IU} / \mathrm{mL}$ \\
\hline $\mathrm{TgAb}$ & $<10 \mathrm{IU} / \mathrm{mL}$ \\
\hline TPOAb & $<5 \mathrm{IU} / \mathrm{mL}$ \\
\hline \multicolumn{2}{|c|}{ Blood gas analysis (RA) } \\
\hline $\mathrm{pH}$ & 7.443 \\
\hline $\mathrm{pO}_{2}$ & $68.8 \mathrm{~mm} \mathrm{Hg}$ \\
\hline $\mathrm{pCO}_{2}$ & $44.4 \mathrm{~mm} \mathrm{Hg}$ \\
\hline $\mathrm{HCO}_{3}^{-}$ & $29.7 \mathrm{mEq} / \mathrm{L}$ \\
\hline $\mathrm{BE}$ & $5.0 \mathrm{mEq} / \mathrm{L}$ \\
\hline Anion gap & $11.5 \mathrm{mEq} / \mathrm{L}$ \\
\hline \multicolumn{2}{|l|}{ HLA genotypes } \\
\hline \multicolumn{2}{|l|}{$A * 33, D * 44$} \\
\hline $\mathrm{DRB} 1 * 13$ & \\
\hline
\end{tabular}

AcAc: acetoacetic acid; 3-OHBA: 3-hydroxybutyrate; CPR; C-peptide immunoreactivity. Blood gas analysis (RA: room air). Serum CPR was drawn from a vein during morning fasting. with susceptibility to type 1 diabetes in Japanese individuals [2].

Since fluctuating levels of consciousness and decreased food intake became persistent over the course of hospitalization, an injection of bolus insulin on a regular schedule was difficult. Therefore, glycemic control was achieved using a sliding scale of fast-acting insulin before each meal and two units of insulin glargine as a basal insulin. The patient was bedridden and needed assistance eating; therefore, she was transferred to a nearby hospital on the 17th day of her hospitalization.

Her somnolence tendency persisted during half a day throughout the hospitalization after changing hospital, and dietary intake was unstable. Since her fasting blood glucose level was from 60 to $90 \mathrm{mg} / \mathrm{dL}$ and was found to be stable, insulin glargine was discontinued on the 20th day (third day after changing hospital). Her HbA1c level was gradually improved to $6.5 \%$ on the 87 th day, $6.3 \%$ on the 132 nd day, and $6.1 \%$ on the 160 th day. Her fasting serum C-peptide level was also improved to $1.4 \mathrm{ng} / \mathrm{mL}$ on the 160th day as compared to the value $(0.4 \mathrm{ng} / \mathrm{mL})$ on the admission. The restoration of the endogenous insulin secretion capacity, which reduced the necessary amount of insulin, was considered to be brought as a result of release from glucose toxicity or a honeymoon period. Although her preprandial blood glucose levels were slightly high $(140-220 \mathrm{mg} / \mathrm{dL})$, it was possible to follow up without the need to resume the insulin treatment. Although her tailormade daily food calorie was between 800 and $900 \mathrm{kcal}$, her dietary intake was decreased and unstable. No complications of metabolic imbalance with a regular blood test were also detected after changing hospital. She died of natural causes on about 6 months after changing hospital.

\section{Discussion}

The 2012 Japanese National Health and Nutrition survey estimated that approximately 20.5 million individuals were either strongly suspected of having or potentially had diabetes. Although the number of children and adults among this group is gradually decreasing, the number of elderly individuals is rapidly increasing [3]. However, the subjects included in this report were mostly considered to have type 2 diabetes because type 1 diabetes only accounts for approximately $5 \%$ of all cases diagnosed with diabetes in the Japanese population [4].

Type 1 diabetes is the main type of diabetes in the young, accounting for $85 \%$ or more of all individuals with diabetes in those less than 20 years old worldwide. The incidence rate of type 1 diabetes increases from birth and peaks between the ages of 10 and 14 years [5]. The incidence of type 1 diabetes in adults is generally lower than that in children, with approximately $25 \%$ of those with type 1 diabetes being diagnosed in adulthood. Clinical presentation occurs at all ages and as late as the ninth decade of life. On the other hand, the prevalence of type 1 diabetes in the Japanese population is less than onetenth that in most Caucasian populations. An epidemiological study had not previously been conducted on the prevalence of type 1 diabetes in the elderly in Japan [6]. However, approximately 30 cases of new onset acute-onset type 1 diabetes mel- 
litus, including fulminant cases, aged 75 or older, have been reported since 1997 [7]. Since most of these cases were described in Japanese, they cannot be cited here.

Although she did not have a previous history of diabetes and a family history of type 1 or type 2 diabetes, it was not clear whether she might have been potentially suffering from type 2 diabetes or slow progressive insulin dependent diabetes mellitus (SPIDDM) before the hospitalization. Although type 1 diabetes generally occurs when about $90 \%$ of the body's insulin producing cells have been destroyed, most patients still are producing some insulin at the time that type 1 diabetes is diagnosed. The honeymoon period, which appears shortly after the onset of type 1 diabetes and persists for a few months to a few years, is sometimes experienced. During the honeymoon period, some patients regain beta cell activity transiently and the patient's insulin requirements are minimal and some patients are able to maintain normal or near normal blood glucose with reduced or no use of insulin [8]. Since she died after about 6 months from the onset and could not observe for a long period, it was not clear whether her stage was during the honeymoon period or her condition was SPIDDM. Therefore, we diagnosed with acute-onset type 1 diabetes mellitus based on the diagnostic criteria for acute-onset type 1 diabetes mellitus (2012) by the Committee of the Japan Diabetes Society. To the best of our knowledge, our case is the oldest among elderly patients with new onset acute-onset autoimmune type 1 diabetes mellitus.

The very old, aged 75 or older, are often accompanied by numerous comorbidities and geriatric conditions, so-called frailty. Frailty is defined as a syndrome of decreased reserve and resistance to stressors and is clinically expressed as muscle weakness, poor exercise tolerance, factors related to body composition, sarcopenia, and disability [9]. Antidiabetic therapy for the elderly with frailty such as our case needs to consider not only the standard goal of lowering hyperglycemia levels, but also improvements in the quality of life and life expectancy of patients. However, since there is currently no definitive evidence for the management of blood glucose and $\mathrm{HbA} 1 \mathrm{c}$ in the elderly with diabetes, treatment guidelines based on data extrapolation from younger adults and expert opinions cited from reliable evidence are applied. According to some of these guidelines, moderate glycemic control (HbA1c 7-8.5\%) is considered appropriate for the elderly with frailty to avoid severe hypoglycemia $[10,11]$.

Insulin therapy is required in the treatment of type 1 diabetes in order to prevent serious states such as severe hyperglycemia and diabetic ketoacidosis. The multiple daily injection (MDI) regimen composed of basal and bolus insulin is generally used to treat type 1 diabetes. However, older adults have multiple comorbidities, functional disabilities, erratic food intake, and insufficient social support [12]. The elderly may present with less typical symptoms of hyperglycemia or hypoglycemia than those of healthy individuals because of variable dietary habits and a poorer ability to recognize and relate these symptoms. In order to prevent severe hyperglycemia and hypoglycemia, insulin treatment strategies and delivery approaches must be individualized and differentiated between healthy older adults and those with frailty and limited life expectancy, such as the present case. Therefore, clinical, functional, and psychosocial factors need to be identified and addressed when developing treatment plans. In the present case, the ability of our patient to learn the manipulation of insulin self-injections and self-monitoring of blood glucose levels was low because she exhibited cognitive impairments and repeated disturbances of consciousness regardless of her blood glucose levels. Although extreme hyperglycemia and hypoglycemia were not detected after her admission, she had repeated somnolence during hospitalization. Although the influence of her advanced age was considered as a cause of somnolence, a definitive cause could not be determined. Since food intake varied at each meal, the amount of which was small, glycemic control was also unstable. Therefore, it was impossible to fix an amount of bolus insulin, and a sliding scale of fast-acting insulin before each meal and insulin glargine as a basal insulin were used to achieve glycemic control.

Class II HLA-DR and $-D Q$ genes are known to be associated with type 1 diabetes in almost all ethnic groups. However, the relevant alleles and haplotypes differ among each ethnic group. The DR4 (DRB1*04:05-DQB1*04:01) and DR9 $(D R B 1 * 09: 01-D Q B 1 * 03: 03)$ haplotypes have been linked to the development of type 1 diabetes in Japanese and most eastAsian populations [2]. On the other hand, the DR2 haplotype $(D R B 1 * 15: 01-D Q B 1 * 06: 02)$ is negatively associated with type 1 diabetes in the Japanese population. In the present case, her haplotypes were unrelated to the above-described susceptible or insusceptible gene.

\section{Conclusion}

Older adults with type 1 diabetes are a heterogeneous group. Although epidemiological studies are important for contributing to better therapeutic approaches, the prevalence of elderly individuals with type 1 diabetes is very low in Japan and, thus, has not been examined in detail. The treatment plan for elderly individuals with type 1 diabetes, especially when accompanied by frailty, needs to focus on preventing hypoglycemia and severe hyperglycemia, and address individualized physical, emotional, and social challenges in order to enhance the safety and quality of life of patients. This case revealed that acute type 1 diabetes may develop not only in the young-old or old-old, but also in the ultra-elderly. To the best of our knowledge, our case is the oldest among elderly patients with new onset acute-onset autoimmune type 1 diabetes mellitus in Japan.

\section{Competing Interests}

The authors declare that there is no conflict of interest regarding the publication of this paper.

\section{References}

1. Kawasaki E, Maruyama T, Imagawa A, Awata T, Ikegami $\mathrm{H}$, Uchigata Y, Osawa $\mathrm{H}$, et al. Diagnostic criteria for acute-onset type 1 diabetes mellitus (2012): Report of the Committee of Japan Diabetes Society on the Research of 
Fulminant and Acute-onset Type 1 Diabetes Mellitus. J Diabetes Investig. 2014;5(1):115-118.

2. Ikegami H, Noso S, Babaya N, Kawabata Y. Genetics and pathogenesis of type 1 diabetes: prospects for prevention and intervention. J Diabetes Investig. 2011;2(6):415-420.

3. Yokono K. Total management of diabetes mellitus in the elderly. Diabetol Int. 2014; 5:155-157.

4. International Diabetes Federation. Diabetes Atlas, 6th ed. 2013.

5. Maahs DM, West NA, Lawrence JM, Mayer-Davis EJ. Epidemiology of type 1 diabetes. Endocrinol Metab Clin North Am. 2010;39(3):481-497.

6. Kawasaki E, Matsuura N, Eguchi K. Type 1 diabetes in Japan. Diabetologia. 2006;49(5):828-836.

7. Tsuji H. [A very elderly case of acute-onset autoimmune type 1 diabetes mellitus]. Nihon Ronen Igakkai Zasshi.
2010;47(6):622-626.

8. Moole H, Moole V, Mamidipalli A, Dharmapuri S, Boddireddy R, Taneja D, Sfeir H, et al. Spontaneous complete remission of type 1 diabetes mellitus in an adult - review and case report. J Community Hosp Intern Med Perspect. 2015;5(5):28709.

9. Abbatecola AM, Olivieri F, Corsonello A, Strollo F, Fumagalli A, Lattanzio F. Frailty and safety: the example of diabetes. Drug Saf. 2012;35(Suppl 1):63-71.

10. Abbatecola AM, Paolisso G, Sinclair AJ. Treating diabetes mellitus in older and oldest old patients. Curr Pharm Des. 2015;21(13):1665-1671.

11. IDF Working Group. IDF Global Guideline for Managing Older People with Type 2 Diabetes. Epub. 2013.

12. Dhaliwal R, Weinstock RS. Management of Type 1 Diabetes in Older Adults. Diabetes Spectr. 2014;27(1):9-20. 